\title{
РАЗРАБОТКА НОВОЙ КЕРАМИЧЕСКОЙ НАСАДКИ ДЛЯ АБСОРБЦИОННЫХ АППАРАТОВ, ОБЛАДАЮЩЕЙ БОЛЬШЕЙ УДЕЛЬНОЙ ПОВЕРХНОСТЬЮ
}

\author{
Андрей Соколов ${ }^{1}$, Александр Пушнов ${ }^{2}$, Михаил Лагуткин ${ }^{3}$, \\ Екатерина Петрашова ${ }^{4}$, Иван Сидельников ${ }^{5}$, Светлана Маслова ${ }^{6}$ \\ Московский государственный университет инженерной экологии \\ 1, 3, 4, Кафедра автоматизированного конструирования машин и аппаратов, \\ ${ }^{2}$ Кафедра промышленной экологии, \\ ${ }^{5}$ Кафедра процессов и аппаратов химических технологий, \\ Старая Басманная ул., 21/4, 105066 Москва, Россия \\ Эл.nочma: SokolovAS84@mail.ru \\ Поступила 27 ноября 2008; принята 4 декабря 2009
}

\begin{abstract}
Резюме. Приведены результаты гидравлических испытаний новой эффективной керамической насыпной насадки для аппаратов очистки газовых выбросов. Новая кольцевая насадка из керамики выполнена в виде двух полуколец, соединенных между собой общей квадратной перегородкой. При этом полукольца повернуты относительно друг друга на $90^{\circ}$, имеют сквозные отверстия и гофры, расположенные по наружной поверхности. Разработанная насадка имеет более развитую поверхность по сравнению с кольцами Рашига. По результатам испытаний установлено, что новая насадка типа N3C может быть использована в качестве альтернативы кольцам Рашига в установленных диапазонах нагрузок при осуществлении процесса абсорбции.
\end{abstract}

Ключевые слова: насадка, абсорбция, очистка газовых выбросов, сернистый ангидрид, гидравлическое сопротивление, удельная поверхность.

\section{1. Введение}

Вопросам охраны окружающей среды всегда уделялось большое внимание. В настоящее время первостепенное значение приобрели проблемы рационального использования природных ресурсов и защита окружающей среды от загрязнений выбросами промышленных предприятий. Разрабатываемым методам очистки газов присущи как преимущества, так и недостатки при применении к конкретным источникам выбросов. Они, как правило, односторонне переводят токсичные вещества в менее токсичные с большим значением предельно допустимой концентрации (ПДК), поглощая газообразные вещества жидкой фазой. Среди газообразных соединений немало летучих органических веществ (ЛОВ), которые выделяются на предприятиях химической и нефтяной промышленности (Zigmontienè, Baltrènas 2004). В связи с этим актуальной задачей для нефтеперерабатывающих и металлургических предприятий является исключение выбросов в атмосферу с промышленными газами вредных и ядовитых веществ, прежде всего сернистого ангидрида. Для очистки воздуха от ЛОВ в настоящее время наибольшее распространение получил процесс абсорбции.

Наиболее массовыми загрязнителями атмосферы являются пыль, двуокись серы, окись углерода, различные углеводороды и др.

При этом двуокись серы остается одним из основных загрязнителей повсеместно, особенно в рай- онах, расположенных вблизи предприятий по выплавке металлов, нефтеперерабатывающих заводов и крупных тепловых электростанций.

Содержание серы в нефти в среднем составляет 1,2\%. Газы, образующиеся в результате нефтепереработки, используются главным образом для синтеза органических продуктов и для бытовых нужд. При этом содержание сероводорода в газах не должно превышать ПДК, поэтому очистка газов от нефтепереработки необходима и производится на большинстве действующих заводов.

Вопросами очистки отходящих газов от двуокиси серы и ее использования в различных отраслях промышленности занимаются уже давно. Известно много способов ее улавливания, имеющих как достоинства, так и недостатки.

Наиболее целесообразным и эффективным способом утилизации сернистых газов в нефтепереработке и металлургии является переработка их в серную кислоту.

Для более полного использования серосодержащих газов и извлечения серы из технологических газов используют схему двойного контактирования с двойной абсорбцией, в аппаратурное оформление которой входят сушильные башни и абсорберы, загруженные керамической насадкой.

К насадочным элементам предъявляются следующие требования (Лаптев и др. 2001): 
- высокая эффективность (более низкая высота, эквивалентная теоретической тарелке (ВЭТТ), или более высокие коэффициенты массопередачи);

- высокоразвитая удельная поверхность;

-отсутствие застойных зон во внутренней полости элементов насадки;

- низкое гиравлическое сопротивление;

- высокая пропускная способность;

- малая удерживающая способность.

Применительно к геометрическим характеристикам насадки это означает, что удельная межфазная поверхность и доля свободного объема насадочного слоя должны быть высокими.

Особенности коррозионной среды при осуществлении технологического процесса в скрубберных аппаратах сероочистки, а также сравнительно низкая стоимость; износостойкость при контакте с потоком сырья, содержащим твердые частицы; большая удельная поверхность; прочность на разрыв и крипоустойчивость при высоких температурах; стойкость к окислению (Миллс 2004) обуславливают использование керамических материалов при изготовлении насадок.

Однако использование керамики существенно увеличивает толщину стенки и удельный вес слоя насадки. Классификация керамических насыпных насадок приведена на рис. 1.

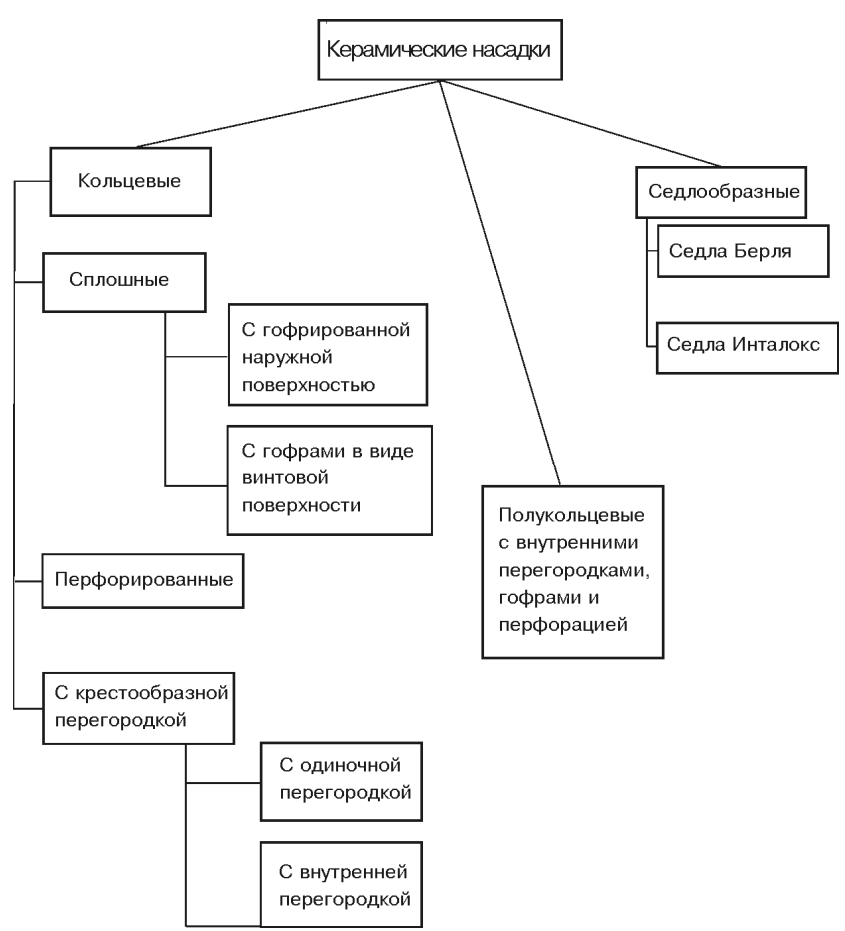

Рис. 1. Классификация керамических насыпных насадок

Fig. 1. Classification of ceramic random packing

В настоящее время в скрубберных аппаратах сероочистки используют в основном кольца Рашига, удельная поверхность которых невысока, а внутренняя полость при загрузке внавал плохо омывается контактирующими потоками. В настоящей статье описываются результаты испытаний новой кольцевой керамической насадки, отличающейся более развитой удельной поверхностью и лучшей омываемостью всей внутренней поверхности.

\section{2. Методы интенсификации процесса массообмена в нерегулярных слоях насадки}

Анализ конструкций и гидродинамической обстановки в аппаратах, характерной для насадок различного типа, показывает следующее.

Перфорация элементов насадки обеспечивает более равномерное распределение и перераспределение жидкости и газовой фазы, более полное использование геометрической поверхности насадки, а также более интенсивное обновление поверхности контакта фаз.

Всевозможные завихрители, лопасти, выступы и прочие конструктивные элементы насадки способствуют турбулизации жидкости, ее диспергированию, завихрению потоков газа. При этом, однако, неминуемо увеличивается гидравлическое сопротивление и снижается предельная нагрузка. Поэтому работы по интенсификации процесса массообмена следует вести в направлении поиска таких оптимальных конструктивных решений насадки, которые, максимально увеличивая интенсивность процесса массообмена, одновременно минимально увеличивали бы гидравлическое сопротивление.

Целесообразны такие конструктивные приемы, как нанесение на поверхность элементов насадки гофр или ее рифление с целью удлинения пути потоков, то есть развитие поверхности контакта взаимодействующих фаз, дополнительная турбулизация потоков.

Снабжение элементов насадки перегородками и другими дополнительными внутренними поверхностями увеличивает механическую прочность элементов и способствует развитию поверхности контакта фаз. При этом, однако, растет сопротивление и снижается пропускная способность слоя насадки. Рост гидравлического сопротивления приводит к увеличению энергетических затрат, а уменьшение пропускной способности значительно увеличивает диаметр колонны и тем самым ее металлоемкость (Каган $u$ дp. 2008). Эффективность насадки может быть достигнута лишь в том случае, если будет обеспечено омывание всей внутренней и наружной поверхности элемента насадки.

На рис. 2 приведены данные по гидравлическому сопротивлению некоторых наиболее распространенных промышленных насадок из керамики и полимерных материалов (Pushnov et al. 2008). Сведения об удельной поверхности приведены в табл. 1 (Billet, Schultes 1990).

Как правило, насадки, имеющие большую удельную поверхность, имеют большее гидравлическое сопротивление. Из сопоставления данных рис. 2 и таблицы 1 видно, что кольца Палля (кривая 2 на рис. 2), имеющие удельную поверхность, приблизи- 
тельно равную седлам Инталокс (кривая 1 на рис. 2), обладают меньшим гидравлическим сопротивлением. Отсюда можно заключить, что на гидравлическое сопротивление влияет не только удельная поверхность, но и форма.

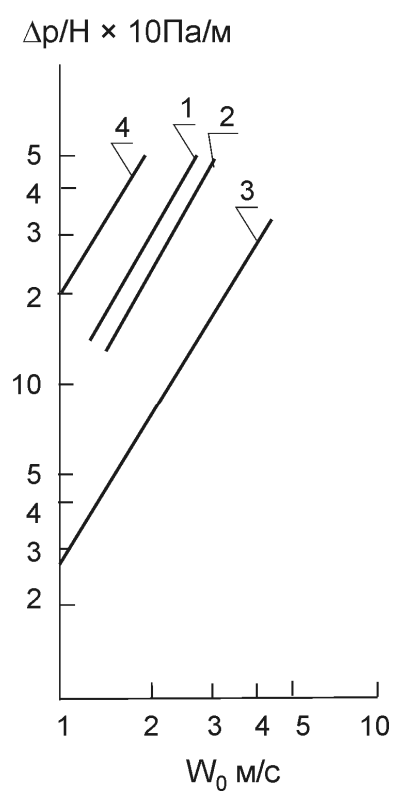

Рис. 2. График зависимости сопротивления слоя насадки $\Delta \mathrm{P} / \mathrm{H}$ от скорости воздуха $\mathrm{W}_{0}$ на полное сечение пустого аппарата: 1 - седла Инталокс, керамические, $50 \times 50 ; 2$ - кольца Палля, керамика, $50 \times 50 ; 3$ - регулярно уложенные кольца ПСЛ типа; 4 - регулярно уложенные кольца ПСЛ макс. типа

Fig. 2. Schedule of dependence of resistance of a layer of packing $\Delta \mathrm{P} / \mathrm{H}$ on air speed $\mathrm{W}_{0}$ on full section of the empty device: 1 - Ceramic Intalox saddles, 50×50; 2 - Ceramic Pall rings, 50 $\times 50 ; 3-$ Regular rings PSL type; 4 - Regular rings PSImax type

Обсуждение достоинств и недостатков используемых в промышленности нерегулярных насадок из металла, а также насадок из керамики и других материалов содержится в работах ученых (Billet, Schultes 1990; Лаптев 2007; Леонтьев, Сидоров 2004; Пушнов, Сакалаускас 2008; Baltrenas et al. 2004).

Таблица 1. Удельная поверхность насадок

Table 1. Specific surface of packing

\begin{tabular}{l|c|c|c}
\hline \multicolumn{1}{c|}{ Тип } & Материал & $\begin{array}{c}\text { Размер, } \\
\text { мм }\end{array}$ & $\begin{array}{c}\text { Удельная площадь } \\
\text { поверхности, }{ }^{2} / \mathrm{M}^{3}\end{array}$ \\
\hline $\begin{array}{l}\text { Кольца } \\
\text { Палля }\end{array}$ & Керамика & 50 & 116,5 \\
\hline \multirow{2}{*}{$\begin{array}{l}\text { Кольца } \\
\text { Хифлоу }\end{array}$} & Керамика & 75 & 54,1 \\
\cline { 3 - 4 } $\begin{array}{l}\text { Кольца } \\
\text { Рашига }\end{array}$ & Керамика & 25 & 89,7 \\
\cline { 3 - 4 } $\begin{array}{l}\text { Седла } \\
\text { Инталокс }\end{array}$ & Керамика & 50 & 108,3 \\
\hline
\end{tabular}

Анализ конструкций нерегулярных насадок, созданных в последние годы, показывает, что каждое новое конструктивное решение дает незначительный выигрыш в пропускной способности и гидравлическом сопротивлении и в еще меньшей степени в эффективности. Попытки увеличить эффективность за счет развития геометрической поверхности элементов ведут к снижению пропускной способности и усложнению конструкции. В то же время стремление увеличить пропускную способность и улучшить омываемость всей поверхности элемента путем его перфорирования ведет к снижению поверхности контакта фаз. Таким образом, в настоящее время актуальна задача поиска таких новых конструктивных решений, крупносерийное производство которых при сохранении или некотором улучшении основных показателей будет простым и дешевым.

\section{3. Новая кольцевая насадка}

При разработке новой конструкции насадки из керамики в качестве аналога была использована насадка типа ГИАП-НЗ, которая представляет собой два полукольца, соединенных квадратной перегородкой и повернутых относительно друг друга на $90^{\circ}$ (Каган и др. 1992). На каждом полукольце имеется зазор, расположенный в середине полукольца (Рис. 3).

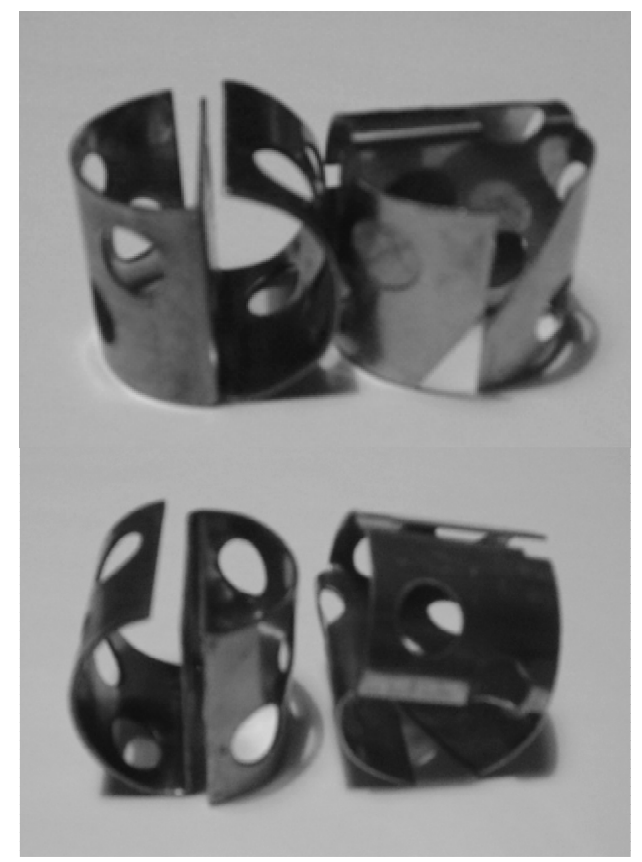

Рис. 3. Аналог новой насадки $\mathrm{N} 3 \mathrm{C}$ - насадка ГИАП-Н3

Fig. 3. Analogue new packing N3C - packing GIAP-N3

Недостатками данной насадки является недостаточная турбулизация, эффективность тепло- и массообмена, жесткость, коррозионная стойкость в агрессивных средах, высокая стоимость.

Наличие у насадки сквозных отверстий круглой формы и равномерно расположенных продольных выступов позволяет увеличить удельную поверхность насадки и создать дополнительные местные завихрения жидкостного и газового потока, улучшить условия для межфазного перемешивания, т.е. усилить 
турбулизацию и повысить кратность обновления поверхности контакта взаимодействующих фаз, что приводит к повышению эффективности тепло- и массообмена, а также повышению жесткости.

Выполнение полуцилиндра и перегородки без зазоров способствует повышению жесткости.

Задачей изобретения было создание конструкции насадки, позволяющей повысить турбулизацию потока, эффективность тепло- и массообмена, жесткость, коррозионную стойкость и снизить стоимость.

Разработанная насадка из керамики также выполнена в виде двух полуколец, соединенных перегородкой. Однако в отличие от аналога снабжена гофрами по образующей каждого полукольца, причем в полукольцах и перегородке выполнены сквозные отверстия круглой формы.

Общий вид разработанной насадки представлен на рис. 4.

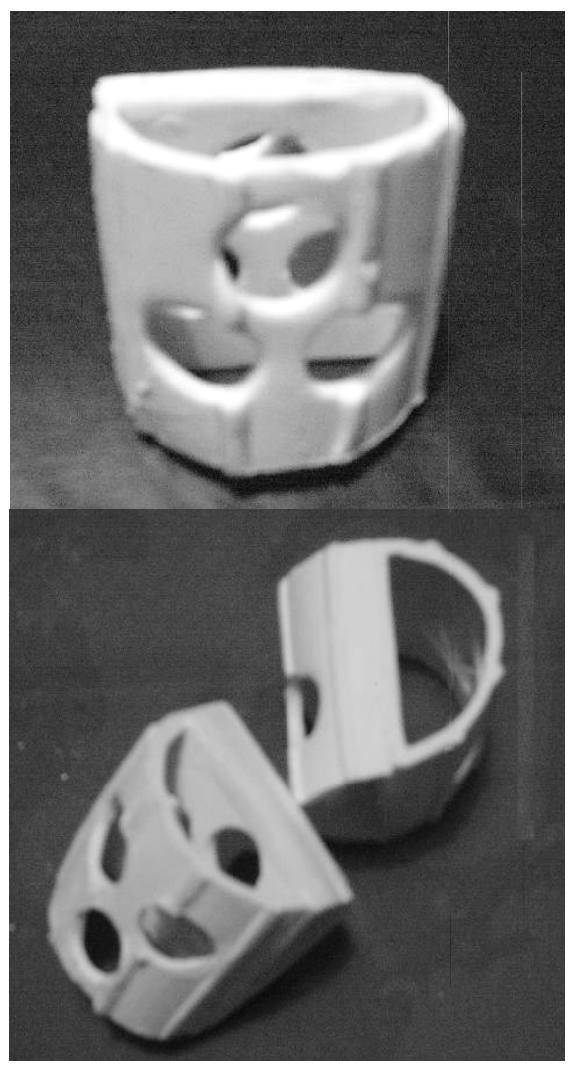

Рис. 4. Новая керамическая насадка $\mathrm{N} 3 \mathrm{C}$

Fig. 4. New ceramic packing N3C

\section{4. Опытная установка и методика проведения эксперимента}

Принципиальная схема установки показана на рис. 5 . Общий вид установки с колонным аппаратом, загруженным керамической насадкой N3C размерами $50 \times 50 \times 5$ мм, показан на рис. 6 .

Установка состоит из колонны 1 с керамической насадкой, воздуходувки 2, измерителя расхода воздуха 3 (диафрагменного типа), дифференциальных манометров 4а и 46 (с электрическим выходом) и обслуживающей ЭВМ с дисплеем 5.

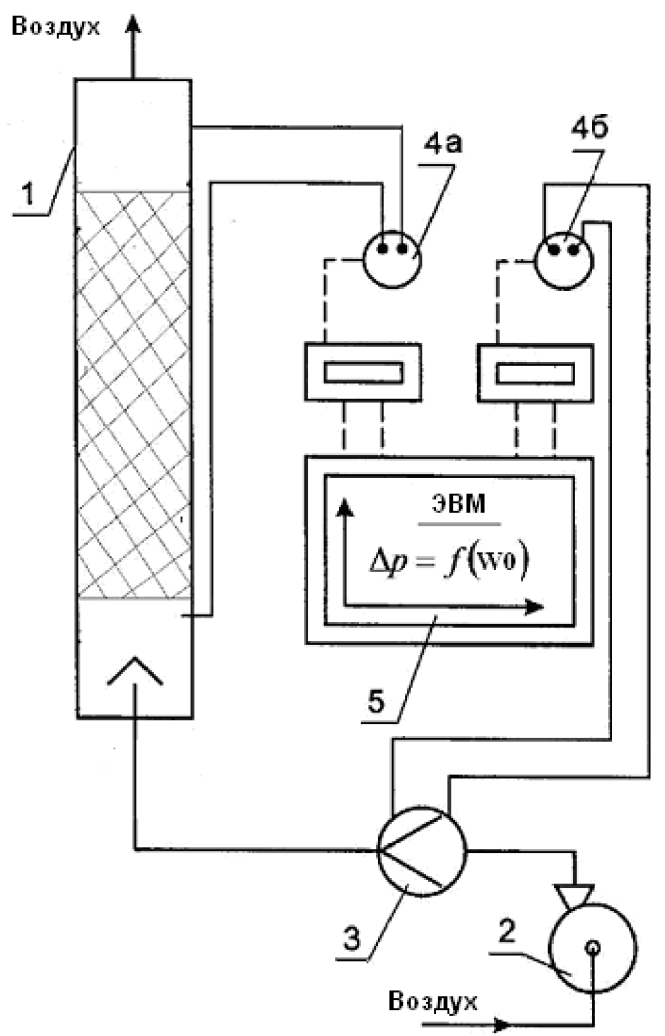

Рис. 5. Схема опытной установки: 1 - колонна; 2 воздуходувка; 3 - измеритель расхода воздуха; 4 манометры; 5 - ЭВМ

Fig. 5. Scheme of experimental equipment: 1 - column; 2 - air tank; 3 - air consumption measuring instrument; 4 - manometer; 5 - IBM

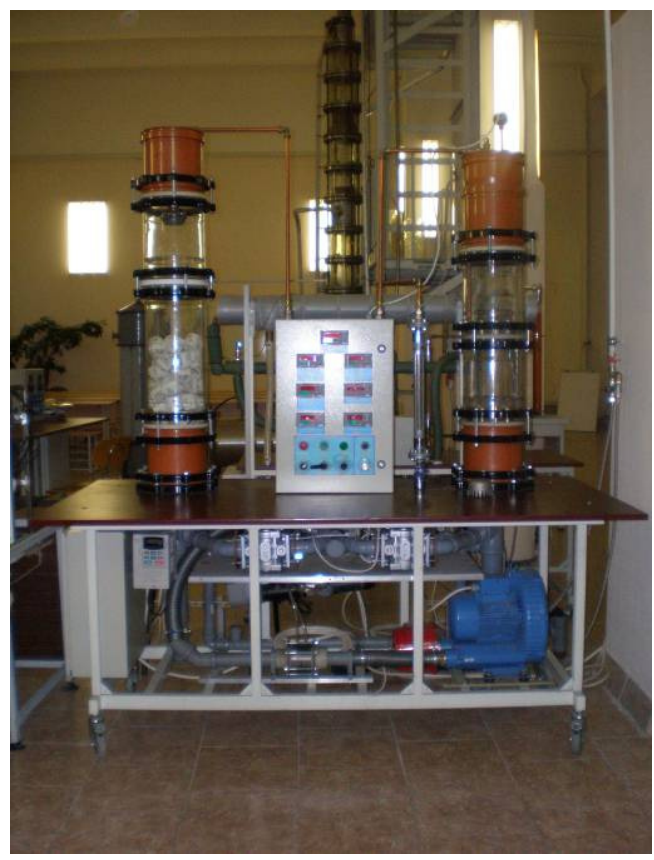

Рис. 6. Общий вид лабораторной установки с насадкой N3C

Fig. 6. General view of experimental equipment with packing $\mathrm{N} 3 \mathrm{C}$ 
В колонну поочередно загружались керамические насадки следующих типов: новая насадка N3C и кольца Рашига с размерами $50 \times 50 \times 5$ мм.

Воздух воздуходувкой 2 через измеритель расхода 3 подавался в колонну 1. Дифференциальными манометрами 4а и 46 замерялись соответственно перепад давления в колонне и расход подаваемого воздуха. В ЭВМ эта информация преобразовывалась и выдавалась в цифровом виде в виде зависимости гидравлического сопротивления насадки от скорости воздуха в колонне. Измерения гидравлического сопротивления слоя насадки проводились при расходах воздуха в диапазоне от $8,7 \mathrm{~m}^{3} /$ ч до $123 \mathrm{~m}^{3} /$ ч.

Скорость воздуха в расчете на полное сечение пустого аппарата $\mathrm{W}_{0}$ изменялась в интервале от $0,06 \mathrm{~m} / \mathrm{c}$ до $0,9 \mathrm{~m} / \mathrm{c}$.

\section{5. Результаты}

Характеристики испытуемых насадок типа N3C и колец Рашига приведены в табл. 2.

Таблица 2. Характеристика испытуемых насадок

Table 2. Characteristic of examined packing

\begin{tabular}{l|c|c}
\hline Тип насадки & $\begin{array}{c}\text { Доля свободного } \\
\text { объема (порозность) } \\
\mathrm{m}^{3} / \mathrm{M}^{3}\end{array}$ & $\begin{array}{c}\text { Удельная площадь } \\
\text { поверхности, } \\
\mathrm{m}^{2} / \mathrm{m}^{3}\end{array}$ \\
\hline Кольца Рашига & 0,78 & 87,5 \\
\hline $\mathrm{N} 3 \mathrm{C}$ & 0,88 & 97 \\
\hline
\end{tabular}

Как видно из табл. 2, новая насадка N3C обладает по сравнению с кольцами Рашига большей удельной площадью поверхности (на 10\%) и большей долей свободного объема (на 10\%), что объясняется более развитой удельной поверхностью новой насадки.

Результаты опытов обрабатывались в виде зависимости $\Delta P / H=f\left(W_{0}\right)$ в расчете на слой насадки высотой $H=1$ м. На рис. 7 и 8 приведены результаты обработки полученных нами опытных данных испытанных неорошаемых насадок.

Как видно из графиков, представленных на рис. 7 и 8, насадка N3C по сравнению с кольцами Рашига при скорости воздуха, равной 0,5 м/с, имеет несколько меньшее гидравлическое сопротивление.

На рис. 9 приведено сравнение полученных нами результатов, обработанных в виде зависимости $\Delta P / H=f\left(W_{0}\right)$, для колец Рашига с опытными данными Жаворонкова и Хоблера для колец Рашига тех же размеров и из того же материала.

Из данных, приведенных на рис. 9, видно, что наши опытные данные совпадают с опытными данными Жаворонкова и Хоблера с погрешностью $\pm 10 \%$, что указывает на достоверность полученных нами результатов (Жаворонков 2007; Хоблер 1964).

Экспериментальные данные по гидравлическому сопротивлению слоя сухой насадки обработаны в виде зависимости критерия Эйлера $(\mathrm{Eu})$ от числа Рейнольдса $(\mathrm{Re})$.

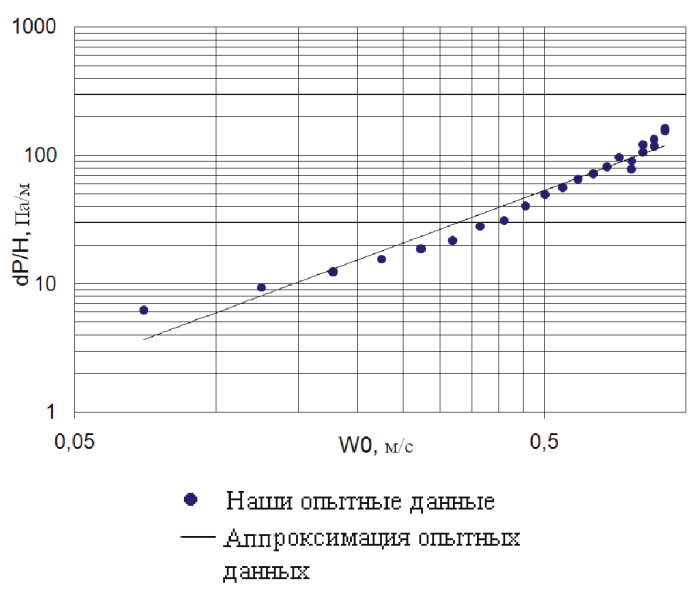

Рис. 7. График зависимости гидравлического сопротивления слоя насадки из $\mathrm{N} 3 \mathrm{C} d P / H$ от скорости воздуха $\mathrm{W}_{0}, \mathrm{~m} / \mathrm{c}$

- Experimental data

- Approximation of experimental data

Fig. 7. The schedule of dependence of hydraulic resistance of a layer packing of $\mathrm{N} 3 \mathrm{C} d P / H$ from speed of air $\mathrm{W}_{0}, \mathrm{~m} / \mathrm{s}$

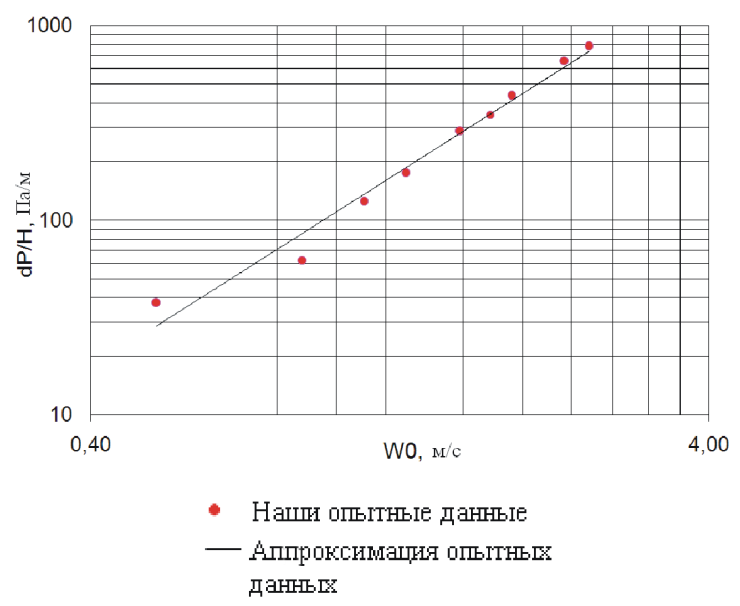

Рис. 8. График зависимости гидравлического сопротивления слоя насадки из колец Рашига $d P / H$ от скорости воздуха $\mathrm{W}_{0}, \mathrm{~m} / \mathrm{c}$.

$$
\begin{aligned}
& \text { - Experimental data } \\
& \text { - Approximation of experimental data }
\end{aligned}
$$

Fig. 8. The schedule of dependence of hydraulic resistance of a layer packing of rings Raschig $d P / H$ from speed of air $\mathrm{W}_{0}, \mathrm{~m} / \mathrm{s}$

Получено следующее критериальное уравнение (1):

$$
\begin{gathered}
\mathrm{Eu}=5090 \mathrm{Re}^{-0.66}, \\
\mathrm{Eu}=\Delta P \cdot \varepsilon^{2} /\left(W_{0}\right)^{2} \cdot \rho, \\
\operatorname{Re}=4 W_{0} \cdot \rho / a \cdot \mu,
\end{gathered}
$$

где: $\Delta P$ - сопротивление 1 м слоя насадки, Па/м; $a-$ удельная площадь поверхности насадки, $\mathrm{m}^{2} / \mathrm{m}^{3} ; \mu-$ динамическая вязкость воздуха при рабочих условиях, Па·с. $\rho$ - плотность воздуха при рабочих условиях, кг $/ \mathrm{M}^{3} ; \varepsilon$ - доля свободного объема слоя насадки, $\mathrm{m}^{3} / \mathrm{M}^{3}$. Зависимость $\mathrm{Eu}=f(\mathrm{Re})$ приведена на рис. 10. 


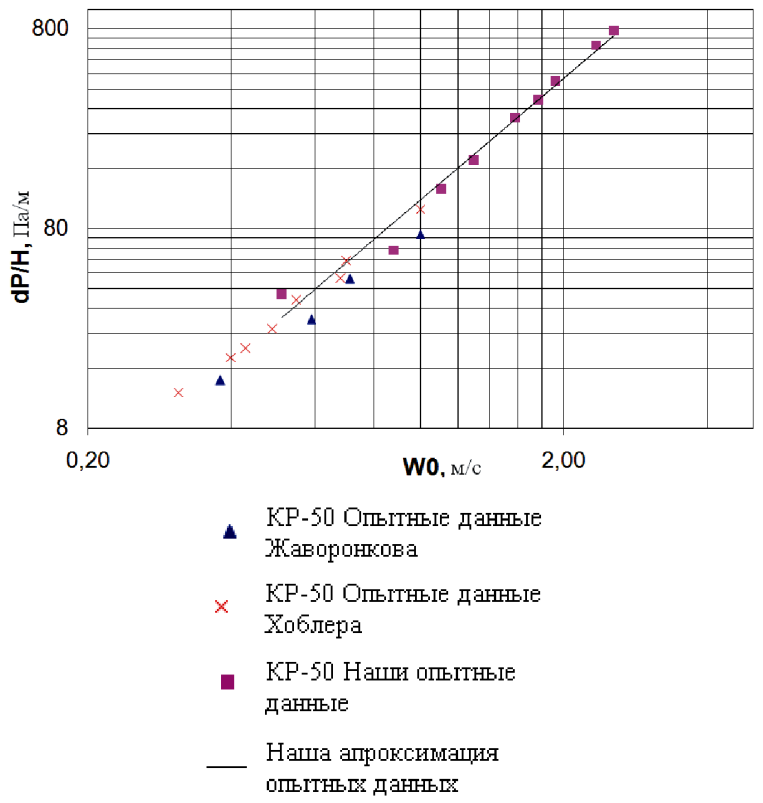

Рис. 9. Сравнение опытных данных с результатами опытов Жаворонкова и Хоблера
KP-50 Experimental data.
of Gavoronkova.
KP-50 Experimental data
of Hoblera.
- KP-50 Our experimental data
_ Approximation of our experimental data

Fig. 9. Comparison of our experimental data with the results of experiments of Gavoronkova and Hoblera

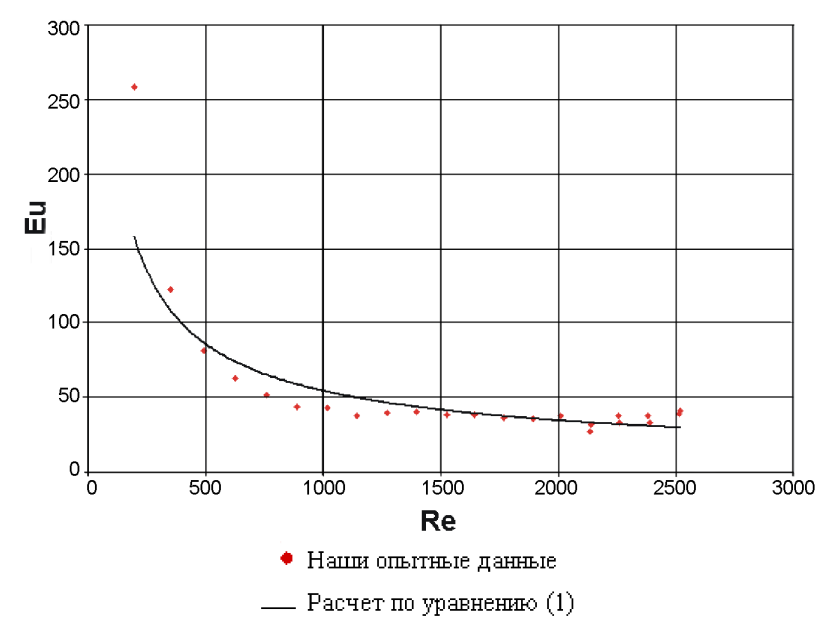

Рис. 10. График зависимости $\mathrm{Eu}=f(\mathrm{Re})$ для насадки типа N3C.

$$
\begin{aligned}
& \text { - Our experimental data } \\
& \text { - Calculation by equation (1) }
\end{aligned}
$$

Fig. 10. Schedule of dependence $\mathrm{Eu}=f(\mathrm{Re})$ for packing type $\mathrm{N} 3 \mathrm{C}$

Полученное уравнение (1) обобщает опытные данные с точностью до $\pm 8 \%$.

\section{6. Выводы}

1. Разработана и испытана новая кольцевая насадка, представляющая собой два установленных под углом $90^{\circ}$ друг к другу полукольца, соединенных между собой перегородкой. В полукольцах и перегородке имеются сквозные отверстия круглой формы. Насадка имеет более высокую развитую удельную поверхность и долю свободного объема, что делает ее перспективной для осуществления процессов теплои массообмена.

2. Определены закономерности изменения гидродинамических параметров новой неорошаемой насадки типа N3C в диапазоне чисел Re от 230 до 2500.

3. Предложено критериальное уравнение для определения гидравлического сопротивления сухой насадки новой конструкции.

4. Достоверность проведенных экспериментов подтверждается сравнением полученных результатов с результатами Хоблера и Жаворонкова для колец Рашига.

\section{Литература}

Каган, А. М.; Гельперин, И. И.; Дильман, В. В.; Юдина, Л. А.; Пальмов, А. А.; Пушнов, А. С. 1992. Высокоэффективное контактное устройство для процессов абсорбции и ректификации - нерегулярная металлическая насадка ГИАП-Н3 [Kagan, A. M., et al. The highly effective contact device for absorption and rectification processes - irregular metal packing ГИАП-Н3], Химическая промышленность 8: 28-34.

Каган, А. М.; Пушнов, А. С.; Чиж, К. В. 2008. Совершенствование конструкций нерегулярных металлических насадок [Kagan, A. M., et al. Perfection of designs irregular metal packing], Химическая промышленность 85(1): 45-48.

Лаптев, А. Г.; Данилов, В. А.; Фарахов, М. И.; Шигапов, И. М.; Кудряшов, В. Н.; Мухитов, И. Х.; Фарафонов, Г. П.; Файзрахманов, Н. Н. 2001. Повышение эффективности узла щелочей очистки пирогаза в производстве этилена [Laptev, A. G., et al. Increase of efficiency of knot of alkalis of clearing phirogas in manufacture ethylene], Химическая промышленность 10: 24-33.

Леонтьев, В. С.; Сидоров, С. И. 2004. Современные насадочные колонны: особенности конструктивного оформления. Энерго- и ресурсосберегающие проиессы в химической технологии, нефтехимии и биологии. Часть 1. Современные направления развития технологии и аппаратурного оформления прочессов ректификачии в спиртовых производствах [Leontjev, V. S.; Sidorov, S. I. Modern packings columns: features of constructive registration. Energo- and resourse-seving processes in chemical technology, petrochemistry and biology. Part 1. Mpodern directions of development of technology and hardware registration of processes of rectification in spirit manufactures]. С.-Петербург: ФГУП «Российский научный центр «Прикладная химия», ООО ПКФ «Спирт», 44-60.

Лаптев, А. Г. 2007. Модели пограничного слоя и расчет тепломассообменных проиессов [Laptev, A. G. Models of an interface and calculation heatweightexchange processes]. Казань: Издательство Казанского университета. $500 \mathrm{c}$. 
Миллс, Д-р Дж. 2004. Решение некоторых проблем при переработке нефти с помощью керамических технологий [Mills, D. D. The decision of some problems at oil refining by means of ceramic technologies], Химическая техника 10: 40-43.

Пушнов, А.; Сакалаускас, А. 2008. Аэродинамика керамических регулярных насадок для тепломассобменных процессов в аппаратах защиты окружающей среды [Pushnov, A.; Sakalauskas, A. Aerodynamics of ceramic regular packing for heatweightexchange processes in devices of protection of environment], Journal of Environmental Engineering and Landscape Management 16(1): 30-37.

Жаворонков, Н. М. 2007. Теоретические основы химической технологии: избранные труды \{Zhavoronkov, N. M. Theoretical bases of chemical technology: the selected works]. Москва: Наука. 351 с.
Хоблер, Т. 1964. Macconepeдача и абсорбиия [Chobler, Т. Weghtexchange and absorption) Ленинград: Издательство «Химия».

Baltrènas, P.; Vaiškūnaitè, R.; Špakauskas, V. 2004. Experimental study and mathematical modeling of biofilter aerodynamic resistance, Journal of Environmental Engineering and Landscape Management 12(3): 79-84.

Billet, R.; Schultes, M. 1990. Modelling of pressure drop in packed columns, Inzynieria chemiezna i procesowa 1: 17-30.

Pushnov, A. S.; Kagan; A. M.; Berengarten, M. G.; Ryabushenko, A. S.; Stemyakov, A. V. 2008. Regular packing for heat and mass exchange processes by the direct contact of phases, Engineering Mehanics 15(1): 13-17.

Zigmontienè, A; Baltrènas, P. 2004. Biological purification of air polluted with volatile organic compounds by using sludge recirculation, Journal of Environmental Engineering and Landscape Management 12(2): 45-52.

\section{NAUJA KERAMINĖ İKROVA SU DIDESNIU SAVITUOJU PAVIRŠIUMI ABSORBCIJOS PRIETAISAMS}

\section{A. Sokolov, A. Pushnov, M. Lagutkin, E. Petrashova, I. Sidelnikov, S. Maslova}

Santrauka

Darbe pristatomi keraminès įkrovos, naudojamos teršalams iš dujų valyti, hidraulinio pasipriešinimo duomenys. Nauja žiedinès formos keramine ikkrova sudaryta iš dviejų pusžiedžių. Abu pusžiedžiai pasukti vienas i kitą $90^{\circ}$ kampu bei sujungti bendra kvadratine pertvara. Ju paviršius yra gofruotas bei su angomis. Ši keraminè įkrova (N3C tipo) tobulesnè, palyginti su Rašigo žiedais. Iš rezultatų akivaizdu, kad ji gali būti sẻkmingai naudojama vietoj Rašigo žiedų absorbcijos procese.

Reikšminiai žodžiai: ikrova, absorbcija, dujų emisijos valymas, anhidridas, hidraulinis pasipriešinimas, savitasis paviršius.

\section{DEVELOPMENT OF NEW CERAMIC PACKING FOR ABSORPTION DEVICES WITH A LARGER SPECIFIC SURFACE}

\section{A. Sokolov, A. Pushnov, M. Lagutkin, E. Petrashova, I. Sidelnikov, S. Maslova}

\section{Abstract}

This paper presents hydraulic test results of a new effective ceramic random packing for gas emission clearing devices. The new ring packing from ceramics is formed of two half-rings connected between themselves by a general square partition. Thus the half-rings are turned from each other at $90^{\circ}$ angle, have apertures and goffers which are located on the external surface. The developed packing has a larger surface in comparison with Raschig rings. By test results it is established that the new packing of the type $\mathrm{N} 3 \mathrm{C}$ can be used as an alternative to the Raschig rings in fixed ranges of loadings at realization of the process of absorption.

Keywords: packing, absorption, clearing of gas emissions, sulphurous anhydride, hydraulic resistance, specific surface.

Andrey SOKOLOV. Doctoral student, Dept of ACMaA, Moscow State University of Environmental Engineering (MSUEE). Publications: author 7 scientific publication.

Aleksandr PUSHNOV. Dr, Dept of Engineering, Moscow State University of Environmental Engineering. Doctor of Science, State Institute of Nitrogen Industry (GIAP) (Russia), 1987. Employment: reader (2005), senior lecturer (2004), Moscow State University of Environmental Engineering (MSUEE), Dept of Engineering Ecology. Head of Laboratory of packing "TSNTU RINVO", Ltd, Moscow (2004). Publications: author of over 110 scientific publications. Research interests: packing for heat and mass transfer processes, aerodynamic industrial packing.

Michael LAGUTKIN. Dr Habil, Prof., Dept of ACMaA Moscow State University of Environmental Engineering (MSUEE). Publications: author of over 100 scientific publications. Research interests: packing for heat and mass transfer processes, aerodynamic industrial packing, gidrociklonirovanie.

Ekaterina PETRASHOVA. Doctoral student, Dept of ACMaA, Moscow State University of Environmental Engineering (MSUEE).

Ivan SIDELNIKOV. Dr, Dept of PAHT, Moscow State University of Environmental Engineering (MSUEE). Publications: author of over 40 scientific publications and 5 copyright certificates. Research interests: hydrodynamics of diphasic systems.

Svetlana MASLOVA. Doctoral student, Dept of ACMaA, Moscow State University of Environmental Engineering (MSUEE). 